\title{
A low-speed generator for energy conversion from marine currents - experimental validation of simulations
}

\author{
K Thomas*, M Grabbe, KYuen, and M Leijon \\ Swedish Centre for Renewable Electric Energy Conversion, Department of Engineering Science, Uppsala University, \\ Uppsala, Sweden
}

The manuscript was received on 8 December 2007 and was accepted after revision for publication on 19 February 2008.

DOI: 10.1243/09576509JPE567

\begin{abstract}
A low-speed permanent magnet (PM) cable wound generator for electrical energy conversion from marine or tidal currents has been designed and constructed. A key feature of this variable speed direct drive generator is its capability to efficiently generate electricity from tidal currents with very low velocities, in the order of $1 \mathrm{~m} / \mathrm{s}$. In arriving at an appropriate design for the generator typical characteristics of tidal currents were considered. Using these characteristics as input, and accounting for the electromagnetic losses, detailed computer simulations using a finite-element method software were carried out to come up with the final design. Various parameters that can influence the generator design are presented.

An experimental set-up has been constructed based on the above-mentioned design in order to study the electrical and mechanical performance of the generator through a variety of experiments. The power input for this set-up is a variable speed motor, capable of operating the generator at rotational speeds of $0-16 \mathrm{r} / \mathrm{min}$, representing tidal currents with very low velocities. The generator presented in this paper may be beneficial for a better understanding of an appropriate design and layout of tidal energy conversion systems.
\end{abstract}

Keywords: finite-element method, marine currents, permanent magnet generator, tidal power

\section{INTRODUCTION}

This paper is devoted to discussing the road map from the conceptual stage of a direct drive generator for energy conversion from marine or tidal currents as presented in reference [1] towards design and construction of the first prototype. Another aim of this paper is to clarify and discuss the design choices that may be encountered while designing a generator suited to the nature of tidal currents.

Marine and tidal currents have been identified as an important future contributor to the global electrical energy production. Studies [2-4] have estimated that the extractable tidal current energy in European waters alone is in the range of 39-58 TWh. A more recent review of the resource has been presented in reference

\footnotetext{
*Corresponding author: Swedish Centre for Renewable Electric Energy Conversion, Department of Engineering Science, Uppsala University, Box 534, Uppsala 75121, Sweden. email: karin.thomas@angstrom.uu.se
}

[5]. Flowing water has a high energy density, which makes it attractive as an energy source, but this also makes it challenging to access. In hydropower stations, dams are used to harness the energy of flowing water in rivers. This has also been applied to tidal currents at e.g. the 240 MW La Rance station [6, 7] and a few smaller stations in Canada, China, and Russia [8, 9]. However, in many sites, where the bathymetry is not that of a narrow channel, dams are not practical. There may also be environmental motives for avoiding dams.

For these reasons, methods of energy conversion where equipment is placed in an unregulated water flow are being investigated. Wind energy converters have similarities with marine current energy converters, but there are also significant differences. For instance, tidal currents are a predictable energy source, which is important for management of power delivery. Furthermore, with a limited rated power output of each device, it is possible to maintain a highcapacity factor throughout the tidal cycle and decrease the differences in power production between spring and neap [10]. 
The nature of a tidal current is site specific. Spring velocities can exceed $7 \mathrm{~m} / \mathrm{s}$ in energetic sites such as the Pentland Firth [11]. However, sites with spring velocities in the range of $2-3 \mathrm{~m} / \mathrm{s}$ are more common. While designing the turbine and generator, even lower velocities should be considered to ensure that the system is capable of delivering power efficiently over a wide range of current velocities.

Tidal energy conversion is a highly interdisciplinary area and the available technology is not yet matured [12]. The authors aim at achieving an efficient low speed energy conversion and to see how closely the technology for energy conversion can match the nature of tidal currents. Of special interest for the authors is to investigate how low tidal current velocities can be utilized, technically and economically, for energy conversion. It is hoped that the information presented in this paper can be beneficial for a better understanding of the concepts and techniques involved in energy extraction from water currents.

The marine current energy converter envisaged by the authors is a vertical axis turbine connected to a direct drive, permanent magnet generator (Fig. 1). Since maintenance is likely to be difficult once the device is installed offshore, it seems reasonable to have a simple system with few moving parts as these can fail and need maintenance. With the variable speed, direct drive approach, both gearbox and blade pitch system are unnecessary. Excluding the gearbox to reduce transmission losses and maintenance has already been implemented in wind energy converters [13-16]. In a variable speed system, it is beneficial to have a high efficiency over a wide range of operation. Hence, one of the design parameters considered is the full range of turbine rotational speeds during the tidal cycle. In this paper, only the design aspects of the generator will be presented.

Previous work by Thomas [1] and Leijon and Thomas [17] focus on the simulations of possible

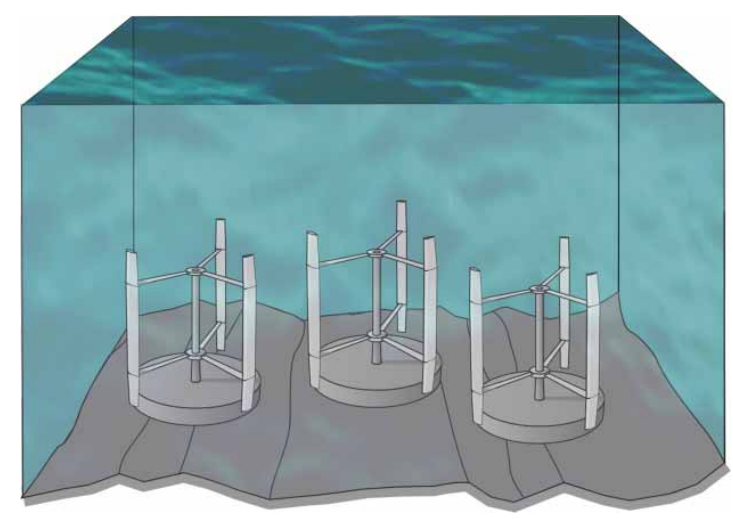

Fig. 1 Illustration of vertical axis turbines coupled to directly driven generators suitable for energy conversion from tidal currents electromagnetic designs and concepts for low-speed PM machines in the range of $1-160 \mathrm{kVA}$. In these publications, the concept of low speed energy conversion is presented without giving full consideration to the constructional requirements of making a prototype machine. Since then, practical issues, such as construction, transportation, structural mechanics, etc. have also been included in the design process. For instance, a prestudy of the experimental set-up in reference [17] was carried out with a fractional winding with $8 / 5$ slots per pole. In the process of finalizing the prototype design, it was found that the stator tooth in the 8/5 design was so narrow that it might be difficult to produce and assemble. Hence, the generator was redesigned with $7 / 5$ slots per pole to ease the construction work, resulting in a decrease in efficiency from 88 to 85 per cent at nominal speed. This was found to be acceptable as the aim of the prototype was to prove the concept, evaluate the finite-element method (FEM) simulation, and to gain confidence for future offshore experiments. This approach, rather than optimizing a few parameters at the design stage, is justified in a system perspective.

The paper is organized as follows. First, the relationship between the tidal current velocity and the possible rotational speeds of the turbine and generator is described. Secondly, modelling aspects and assumptions involved in the generator design are discussed. Finally, constructional aspects of the experimental set-up with the prototype generator are presented.

\section{RELATIONSHIP BETWEEN TIDAL CURRENT VELOCITY AND GENERATOR OR TURBINE ROTATIONAL SPEEDS}

To minimize cavitation, the maximum rotational speed of the turbine is largely decided by the maximum velocity of the tidal currents.

According to Bernoulli's principle [18] the sum of the static and dynamic pressure is always constant for an ideal fluid flow. The motion of a turbine blade relative to the water causes a local pressure drop behind the blade. At high enough velocities, this becomes less than the vapour pressure of water and cavitation occurs. To avoid cavitation an approximate maximum tip speed of the turbine can be derived from Bernoulli's principle

$$
p+\frac{1}{2} \rho \cdot v^{2}+\rho \cdot g \cdot h=\mathrm{const}
$$

In equation (1), $p$ is the atmospheric pressure at sea level, $\rho$ the density of seawater, $v$ the tip speed of the turbine blade relative the water, and $h$ the depth below sea level. 
In practice, the cavitation calculations are complex and depend on turbine design and site-specific variables, e.g. blade profiles, turbine radius, and water depth to name a few. As a rule of thumb, reference [2] suggests that it is advisable to keep the relative velocity below $7 \mathrm{~m} / \mathrm{s}$ to avoid cavitation. A study of the cavitation of a horizontal axis turbine has been presented in reference [19]. In the case presented here, the generator only will be tested in the laboratory without a turbine, and a more generic design approach has been taken. The generator has been designed to operate in a range derived from a hypothetical turbine operated with fixed tip speed ratio (TSR) up to the point where the relative velocity reaches $7 \mathrm{~m} / \mathrm{s}$. At higher current velocities, the turbine will be operated at a lower tip speed ratio.

For a turbine with a radius of $2.5 \mathrm{~m}$, cross-section of $8 \mathrm{~m}^{2}$, and power coefficient of 0.35 , the power will be $4.7 \mathrm{~kW}$ at $10 \mathrm{r} / \mathrm{min}$ in a current of $1.5 \mathrm{~m} / \mathrm{s}$. Keeping a constant TSR until the maximum relative speed of the blade is $7 \mathrm{~m} / \mathrm{s}$, the turbine rotational speed will be limited to $17 \mathrm{r} / \mathrm{min}$ in a current velocity of $2.55 \mathrm{~m} / \mathrm{s}$. The generator output will thus be $23 \mathrm{~kW}$ at $17 \mathrm{r} / \mathrm{min}$ for this particular turbine. Note that the generator is a variable speed machine and it should be designed to work efficiently at a wide range of speeds.

The relationship between the generator and turbine gives two seemingly contradictory needs: to have the best possible efficiency over the whole range of operation and at the same time have good overload capabilities to electrically limit the rotational speed of the turbine during spring tide. In the present work, an average generator speed of $10 \mathrm{r} / \mathrm{min}$ was found adequate based on tidal current velocities, cavitation, and the choice of turbine characteristics.

\section{GENERATOR MODELLING AND DESIGN}

\subsection{Theory and modelling details}

The time varying electromotive force or voltage induced in a generator described by Faraday's law of electromagnetic induction is given by equation (2). In equation (2), $U$ is the induced voltage; $N$ the number of turns in the coil or winding, and $\phi$ the magnetic flux

$$
U(t)=-N \frac{\partial \phi(t)}{\partial t}
$$

In practice, generators suffer from both electromagnetic and mechanical losses. The electromagnetic losses consist of resistive or copper losses in the conductors or windings and iron losses. The iron losses include hysteresis losses, eddy current losses, and excess (or anomalous) losses. In the absence of a gearbox, the mechanical losses are dominated by losses in couplings and bearings. Since these losses are expected to be small, they are not further analysed in the FEM of the generator. Windage losses are also neglected due to the low-rotational speed. That these losses in fact are small for the experimental set-up presented in this paper has been ascertained (see section 4).

The electromagnetic field inside the generator is modelled as a two-dimensional problem. This is a common simplification in radial flux machines [20]. However, if the axial length of the generator is smaller than the diameter of the generator end effects should be taken into account. This is a three-dimensional problem, but two-dimensional approximations of end effects, i.e. end fringing and unequal axial lengths for short machines are discussed in reference [21]. The coil end windings are accounted for by introducing coil end impedances in the circuit equations for the windings (equations (4b) and (4c)).

The complete-generator model is described by a combined set of field and circuit equations. Coupled field and circuit models are now standard for modelling time dependence of electrical fields [22]. The field equation that is solved is given by equation (3)

$$
\sigma \frac{\partial \boldsymbol{A}_{z}}{\partial t}+\nabla \cdot\left(\frac{1}{\mu_{0} \mu_{\mathrm{r}}} \nabla \boldsymbol{A}_{z}\right)=-\sigma \cdot E
$$

In equation (3), $\sigma, \mu_{0}$, and $\mu_{\mathrm{r}}$ are the conductivity, free space permeability, and the relative permeability. $\boldsymbol{A}_{z}$ is the axial magnetic vector potential and $E$ is the applied field. In the circuit equations (4), $I_{a}, I_{b}, I_{c}$ are the conductor currents corresponding to the three phases $a$, $b$, and $c$ of the machine, $U_{a b}$ and $U_{c b}$ are the terminal line voltages between phases $a b$ and $c b$, and $U_{a}, U_{b}, U_{c}$ are the terminal phase voltages obtained from solving the field equations (3). $R_{\mathrm{s}}$ is the coil end resistance and $L_{\mathrm{s}}^{\text {end }}$ describes the coil end inductance

$$
\begin{aligned}
& I_{a}+I_{b}+I_{c}=0 \\
& {\left[\begin{array}{c}
U_{a}+R_{\mathrm{s}} I_{a}+L_{\mathrm{s}}^{\text {end }} \frac{\partial I_{a}}{\partial t}-U_{b} \\
-R_{\mathrm{s}} I_{b}-L_{\mathrm{s}}^{\text {end }} \frac{\partial I_{b}}{\partial t}
\end{array}\right]=U_{a b}} \\
& {\left[\begin{array}{c}
U_{c}+R_{\mathrm{s}} I_{c}+L_{\mathrm{s}}^{\text {end }} \frac{\partial I_{c}}{\partial t}-U_{b} \\
-R_{\mathrm{s}} I_{b}-L_{\mathrm{s}}^{\text {end }} \frac{\partial I_{b}}{\partial t}
\end{array}\right]=U_{c b}}
\end{aligned}
$$

The field equation (3) is solved using a FEM. For better accuracy in the final solutions, shape functions of second degree were used and the meshing was finer close to critical parts of the geometry such as the air gap and conductors, and coarser in the yoke of the stator as shown in Fig. 2. Due to electrical periodicity in the machine, only a few poles are needed to model the generator. Simulations can be performed either in a stationary mode (standstill), where the results 


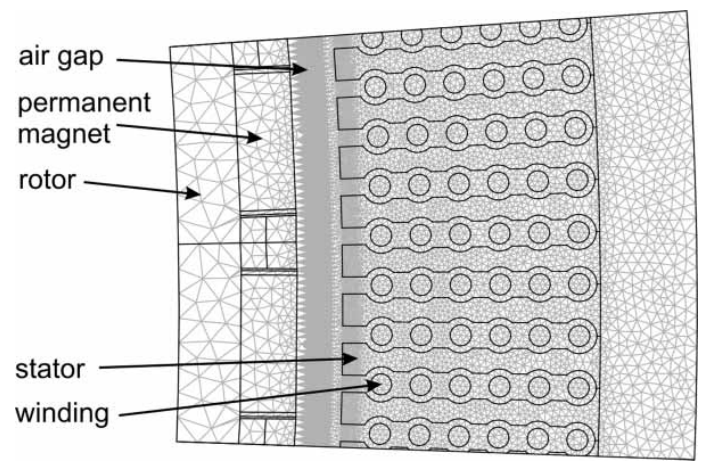

Fig. 2 A screenshot of the mesh details before the calculations are made

are given for a fixed rotor position, or in a dynamic mode (rotating machine scenario). In the dynamic mode, an internal moving boundary technique is used which permits modelling motion without re-creating the FE-mesh [23]. The FEM-based simulation program is based on reference [24].

\subsection{Generator design and assumptions}

The primary aim was to construct a laboratory set-up of the generator in order to study its performance. The experience gained from the construction and testing can be used when designing a robust, efficient, and reliable marine current generator for offshore operation. For the initial design of the generator, stationary mode simulations were carried out. The available space in the laboratory was the first constraint in deciding the generator size: the outer diameter of the machine was fixed to $2 \mathrm{~m}$. Given this constraint, the axial length is largely decided by the chosen design values for the power of the machine, the voltage, and the air gap flux density.

For a machine with variable rotor speeds, it is necessary to design the generator with higher nominal values of voltage and frequency, so that acceptable efficiency is ascertained even when the speed of the rotor is much lower. This can be achieved with a large number of poles, which requires a larger diameter and results in a heavier machine. In this machine, 120 poles could be fitted which results in a frequency of $10 \mathrm{~Hz}$. For the kind of marine current generators proposed, i.e. direct drive with a vertical axis turbine on the same axis of rotation as that of the generator, and with the generator placed on the seabed, it is not necessary to minimize the weight and size of the machine to avoid blockage of the flow through the turbine.

The design of the generator is based on electromagnetic field simulations with data for a hypothetical turbine and plausible water currents as inputs. The hypothetical turbine was given a size $8 \mathrm{~m}^{2}$, a radius of $2.5 \mathrm{~m}$, and a power coefficient $\left(C_{\mathrm{p}}\right)$ of 0.35 . A water current velocity of $1.5 \mathrm{~m} / \mathrm{s}$ was also used to dimension the generator. This results in an energy yield of $5 \mathrm{~kW}$ at $10 \mathrm{r} / \mathrm{min}$ and nominal load. Note that the generator is designed to keep the turbine at a constant tip speed ratio up to the velocity where cavitation is likely to occur. At higher velocities the turbine will be slowed down electromagnetically to operate at a lower $C_{\mathrm{p}}$.

\subsubsection{Stator design}

A cable winding has been found effective in larger machines [25-27] and is here adopted for a smaller machine. The stator is wave wound to achieve lower load angles for a given machine rating compared to a lap winding. The cable used in the present work is a commercial PVC-insulated cable, MK 16 450/750 [28], with a conductor cross-section of $16 \mathrm{~mm}^{2}$ and an average insulation thickness of $1 \mathrm{~mm}$. Experience from the development of cable wound linear generators [29] and wind generators [30] has shown that this cable is convenient from a constructional point of view. Further, a fractional pitch winding is used to prevent cogging and suppress possible harmonics in the machine. However, the authors acknowledge that a fractional pitch winding may not be the most appropriate solution, if the machine is to be connected to the grid via a passive rectifier and an inverter. Under those circumstances, other winding schemes might give a higher power output or other electrical, mechanical, or constructional benefits compared with a fractional pitch winding. Variable speed control of a PM synchronous generator connected to a diode rectifier has been investigated in references [31] and [32]. However, more detailed studies are needed to show which winding scheme and control method could give the highest energy yield over the whole range of operation for a given tidal energy conversion system.

The stator sheet geometry, especially the shape of the stator tooth, was designed to keep the leakage flux to a minimum without significantly increasing the cogging torque or decreasing the flux in the air gap [33]. The stator steel laminations were chosen to be $1 \mathrm{~mm}$ thick, a choice motivated by the low frequency dependant losses of the machine at $10 \mathrm{~Hz}$. The stator material is M800-100A [34].

\subsubsection{Rotor design}

A permanent magnetized rotor was chosen in order to avoid a separate excitation system using, e.g. carbon brushes. However, the fields for PM rotors are uncontrollable and a non-uniform air gap will give rise to non-uniform forces in the air gap, which can lead to vibrations and possibly mechanical damage of the machine. To avoid such problems, an air gap of $10-\mathrm{mm}$ between the rotor and stator was chosen. Another reason for the relatively large air gap was to 
avoid constructional difficulties in the assembly of the first prototype.

In the simulations, the fields from the $\mathrm{Nd}_{2} \mathrm{Fe}_{14} \mathrm{~B}$ magnets [35] are modelled by a current sheet approach [36] that gives equivalent fields produced by fictitious current sheets placed along the non-polar sides of the $\mathrm{PM}$ structure. The rotor material is construction steel with a density of $7800 \mathrm{~kg} / \mathrm{m}^{3}\left(\sigma=2.0 \cdot 10^{6} \mathrm{~S} / \mathrm{m}\right.$ and $\left.\mu_{\mathrm{r}}=965\right)$.

\subsubsection{Simulation results}

The main input parameters for the design of the prototype machine are presented in the second column of Table 1. The machine was built based on this data. However, due to constructional inaccuracies and allowed tolerances, some of the geometrical and winding parameters of the built machine were found to be different from the design values. The measured values presented in the third column of Table 1, have therefore been used for simulations and analysis of the actual experimental set-up.

The input for the simulations includes the parameters mentioned above, as well as additional constraints such as maximum permissible magnetic field at any point in the machine. The output given by the simulations is the axial length and currents (including information about possible harmonics) of the machine. One of the 24 symmetrical cross-sections of the generator is shown in Fig. 3, along with the magnetic field distribution during nominal load conditions. The maximum permissible magnetic field inside the machine was limited to $1.8 \mathrm{~T}$ as the saturation effects are dominant at higher magnetic fields for the chosen stator steel material [34]. Furthermore, the load angle was kept below $10^{\circ}$. This was found necessary to prevent the machine from unstable operation in the event of high-rotational

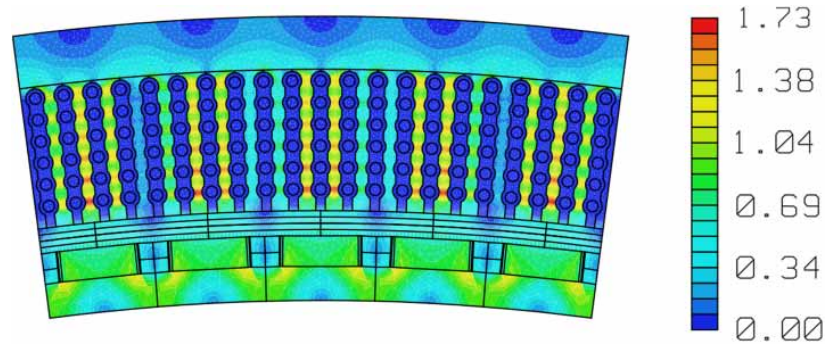

Fig. 3 Illustration of the magnetic field distribution in a symmetrical section of the generator, simulated under nominal-load conditions

speeds or overload conditions, e.g. during spring tide. The design work aimed at having high generator efficiency at rated speed and load of $10 \mathrm{r} / \mathrm{min}$ and $4.5 \Omega /$ phase while keeping the current density low in order to maintain good thermal capabilities at overload. The resulting efficiency and current density at rated load and variable speed are shown in Fig. 4. The efficiency is above 80 per cent in the expected range of operation and the current density is low that implies that there is room for overload without causing the temperature to rise above the thermal limit of the PVC insulation.

\section{GENERATOR CONSTRUCTION AND EXPERIMENTAL SET-UP}

The design of the experimental generator was based on the conditions of the marine and tidal currents as discussed in previous sections. To accommodate the winding scheme, it was found that the length of the end windings had to be increased to an average of $150 \mathrm{~mm}$ (see Table 1). After the rotor was centred and fastened, but before the magnets were mounted,

Table 1 Parameters used in the generator design

\begin{tabular}{lll}
\hline & $\begin{array}{l}\text { Design stage (data } \\
\text { used and/or obtained for the } \\
\text { design of the machine) }\end{array}$ & $\begin{array}{l}\text { Actual prototype (data taken from the } \\
\text { constructed machine and used for } \\
\text { later analyses/simulations) }\end{array}$ \\
\hline Power & $5 \mathrm{~kW}$ & $5 \mathrm{~kW}$ \\
Voltage & $150 \mathrm{~V}$ & $150 \mathrm{~V}$ \\
Nominal speed & $10 \mathrm{r} / \mathrm{min}$ & $10 \mathrm{r} / \mathrm{min}$ \\
Frequency & $10 \mathrm{~Hz}$ & $10 \mathrm{~Hz}$ \\
Outer diameter & $2000 \mathrm{~mm}$ & $2000 \mathrm{~mm}$ \\
Inner diameter & $1835 \mathrm{~mm}$ & $1835 \mathrm{~mm}$ \\
Air gap & $10 \mathrm{~mm}$ & $10.5 \mathrm{~mm}$ \\
Slots per pole & $7 / 5$ & $7 / 5$ \\
Cables per slot & 6 & 6 \\
PM dimensions & $270 \mathrm{~mm} * 32 \mathrm{~mm} * 10 \mathrm{~mm}$ & $68 \mathrm{~mm} 32 \mathrm{~mm} 13 \mathrm{~mm} \mathrm{~m}^{*}$ magnets per pole \\
Rotor ring thickness & 10 & $12-15 \mathrm{~mm}(14.4 \mathrm{~mm})$ \\
Stator height & $270 \mathrm{~mm}$ & $294 \mathrm{~mm}(276 \mathrm{~mm})$ \\
Stacking factor & 1 & 0.956 \\
Coil end winding & $80 \mathrm{~mm}$ & $150 \mathrm{~mm}$ \\
Resistance per phase & $0.48 \Omega$ & $0.47 \Omega$ \\
Load & $4.5 \Omega$ per phase & $4.44 \Omega$ per phase \\
\hline
\end{tabular}




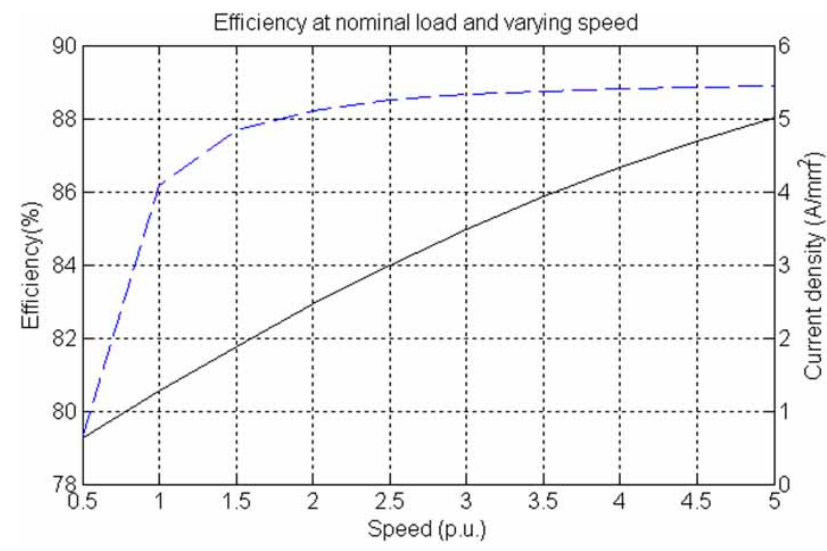

Fig. 4 The dashed line represents the generator efficiency and the solid line the current density at nominal load and variable speed. The rotational speed is given in per unit, where nominal speed is $10 \mathrm{r} / \mathrm{min}$

the friction and windage losses were measured. The generator was permitted to decelerate without excitation (no PM) and with the terminals open circuited according to reference [37]. The frictional torque was measured to $2 \mathrm{Nm}$, or 0.04 per cent of the nominal torque. This can be compared with $1.6 \mathrm{Nm}$ as calculated according to the manufacturer's specifications. The bearings are deep groove ball bearings 6228/C3 with lubricant LGWA2 from SKF [38]. The magnets were inserted in milled grooves in the rotor with the aid of a specially made plastic mould. After construction, the average air gap length of the generator was found to be $10.5 \mathrm{~mm}$, c.f. Table 1 . Figure 5 is a photograph showing the air gap, the magnets inserted in the rotor, and the stator with cables in the stator slots.

As the generator will be run in a laboratory environment without a turbine and water flow, a separate

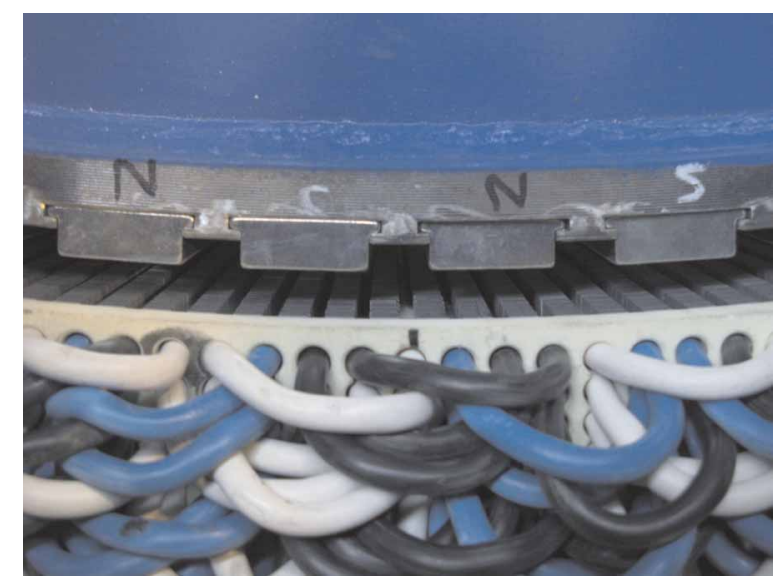

Fig. 5 A photograph showing the air gap, PM, and cable windings

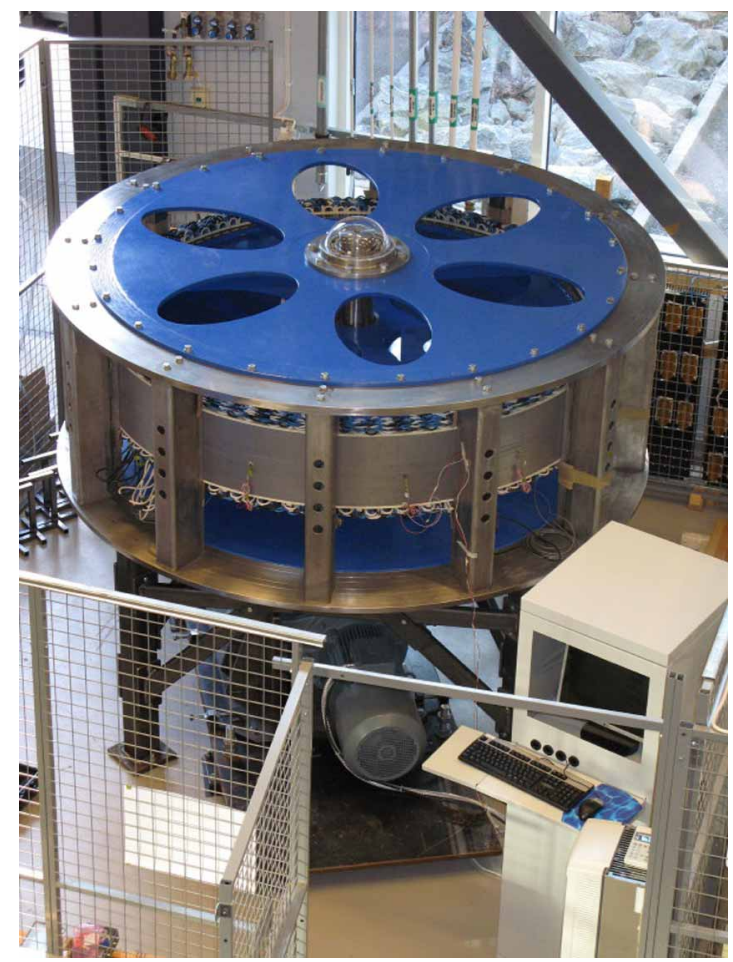

Fig. 6 The experimental marine current generator setup with load and motor drive system

motor drive system is used to run the generator. A $22 \mathrm{~kW}$ four pole induction motor with rated speed and torque of $1500 \mathrm{r} / \mathrm{min}$ and $143 \mathrm{Nm}$, respectively, in conjunction with a gearbox (gear ratio of 89.89) is used [39]. This drive system gives generator rotor speeds in the range of $0-16 \mathrm{r} / \mathrm{min}$ and a maximum torque of $11 \mathrm{kNm}$. Speed control of the motor is achieved using an $\mathrm{ABB}$ frequency converter [40]. This arrangement allows the generator to be run at 60 per cent above the rated speed of $10 \mathrm{r} / \mathrm{min}$, which is necessary in order to study the machine's performance at over load.

In an actual oceanic environment several marine generator units will be connected to passive rectifiers. From the converter station, a DC transmission link will transport the generated power to a final inverter system before connecting to the grid. Due to these system characteristics, the actual load on the marine current generator will be a DC load. For the experimental set-up presented here, the load consists of standard resistors mounted on heat sinks $[\mathbf{4 1}, \mathbf{4 2}]$. The load can be varied by connecting a number of resistors in series and parallel.

The overall experimental set-up with the motor drive system, generator, and load is shown in Fig. 6. Figure 7 shows the measured nominal load voltages from the generator for two different rotor speeds, namely 2 and $16 \mathrm{r} / \mathrm{min}$. The corresponding nominalload voltages predicted by the FEM simulations are also shown in the figure. 


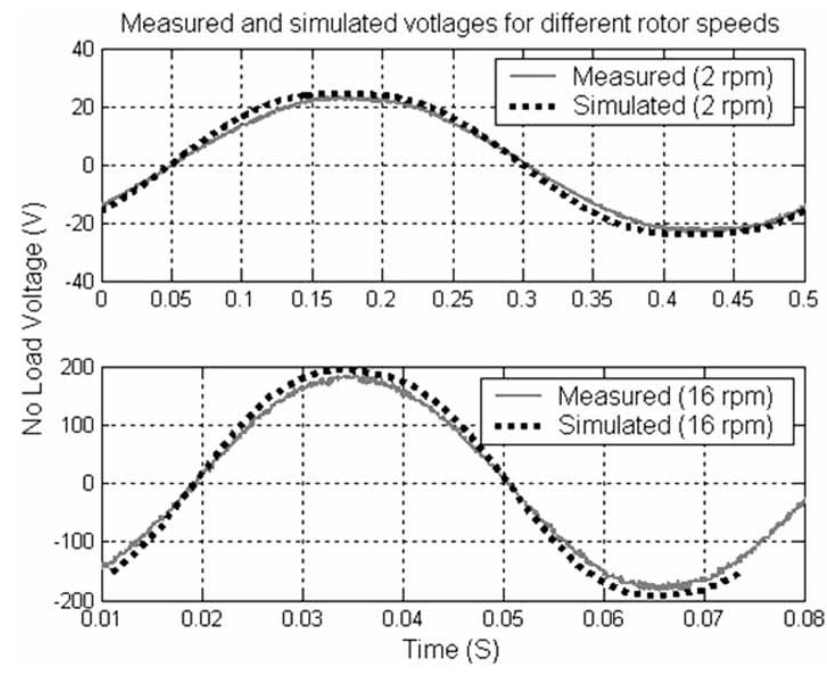

Fig. 7 A comparison of the measured and simulated voltages for the prototype machine at nominal load for two different rotor speeds

\section{CONCLUDING REMARKS}

In this paper, a number of issues encountered when adapting generator design to the nature of marine and tidal currents have been discussed. Such a generator is to operate at low and varying speeds and will consequently have a relatively large diameter. With careful attention to the design of the magnetic circuit, especially the stator tooth geometry and magnet shape [33], it is possible to minimize the leakage flux and to keep a low current density, which are the two important aspects in enabling efficient operation over a wide range of loads and speeds. These issues have been taken into account in the design and construction of a prototype generator, showing that it is possible to transfer these conceptual ideas into a real machine.

As such a generator is in fact feasible, a mechanically simple system is possible. The elimination of components such as a gearbox, excitation system, cooling system, pitching, and yawing mechanisms may be critical in the survivability of marine current energy converters.

\section{ACKNOWLEDGEMENT}

Dr Arne Wolfbrandt and Dr Karl-Erik Karlsson are hereby acknowledged for development of the simulation tool. Sincere thanks to Ulf Ring for supervision and assistance during the construction work.

This work was financially supported by Vattenfall $\mathrm{AB}$ and the Swedish Centre for Renewable Electric Energy Conversion (financed by Uppsala University, The Swedish Agency for Innovation Systems (VINNOVA), and The Swedish Energy Agency (STEM))

\section{REFERENCES}

1 Nilsson, K. Low speed generators for marine current power conversion. UURIE 229-05L, Uppsala, 2005.

2 Non Nuclear Energy - JOULE II, wave energy project results. The exploitation of tidal marine currents. EU JOULE contract JOU2-CT94-0355. Technomare SpA, IT Power Ltd 1996.

3 Black \& Veatch. Tidal stream resource report, peer review issue 1. Report Submission 107799/D/2100/05/1, 2004.

4 Department of Trade and Industry, UK. Tidal Stream Energy Review. ETSU-T/05/00155/REP, 1993.

5 Blunden, L S. and Bahaj, A S. Tidal energy resource assessment for tidal stream generators. Proc. IMechE, Part A: J. Power and Energy, 2007, 221, 137-146.

6 Frau, J. P. Tidal energy: promising projects La Rance, a successful industrial-scale experiment. IEEE Trans. Energy Convers., 1993, 8(3), 552-558.

7 Andre, $H$. Ten years of experience at the "La Rance" Tidal Power Plant. Ocean Management, 1978, 4, 165-178.

8 Hammons, T. J. Tidal power. Proc. IEEE., 1993, 81(3), 419-433.

9 Bernshtein, L. B. Tidal power development - a realistic justifiable and topical problem of today. IEEE Trans. Energy Convers., 1995, 10(3), 591-599.

10 Clarke, J. A., Connor, G., Grant, A. D., and Johnstone, C. M. Regulating the output characteristics of tidal current power stations to facilitate better base load matching over the lunar cycle. Renew. Energy, 2006, 31, 173-180.

11 Bryden, I. G. and Couch, S. J. ME1 - marine energy extraction: tidal resource analysis. Renew. Energy, 2006, 31, 133-139.

12 Bedard, R. Survey and characterization of tidal in stream energy conversion (TISEC) devices. Report: EPRI-TP-004 NA, EPRI, 9 November 2005.

13 Söderlund, L., Eriksson, J.-T., Salonen, J., Vihriälä, H., and Perälä, R. A permanent magnet generator for wind power applications. IEEE Trans. Magnet., 1996, 32(4), 2389-2392.

14 Lampola, P. and Perho, J. Electromagnetic analysis of a low speed permanent magnetized wind generator. In Opportunities and Advances in International Power Generation, Durham, UK, 18-20 March 1996, conference publication number 419 .

15 Spooner, E. and Williamson, A. C. Direct coupled, permanent magnet generators for wind turbine applications. IEE Proc., Electr. Power Appl., 1996, 143(1), 1-8.

16 Wind energy - the facts. An analysis of the wind energy in the EU-25, vol. 1: technology. A report published by The European Wind Energy Association (EWEA), p. 42, available from http://www.ewea.org/index.php?id=91, accessed 12 April 2007.

17 Leijon, M. and Nilsson, K. Direct electric energy conversion system for energy conversion from marine currents. Proc. IMechE, Part A: J. Power and Energy, 2007, 221 (A2), 201-205.

18 Nordling, C. and Österman, J. Physics handbook, 5th edition, 1996 (Studentlitteratur, Lund).

19 Wang, D., Atlar, M., and Sampson, R. An experimental investigation on cavitation, noise and slipstream characteristics of ocean stream turbines. Proc. IMechE Part A: J. Power and Energy, 2007, 221, 219-231. 
20 Craiu, O., Dan, N., and Badea, E. A. Numerical analysis of permanent magnet DC motor performances. IEEE Trans. Magnet., 1995, 31, 3500-3502.

21 Reece, A. B. J. and Preston, T. W. Finite element methods in electrical power engineering, 2000, p. 121 (Oxford science publications).

22 Tsukerman, I. A., Konrad, A., Meunier, G., and Sabonnadiere, J. C. Coupled field-circuit problems: trends and accomplishments. In Digest of the Fifth Biennial IEEE Conference on Electromagnetic Field Computation, 1992.

23 Vassent, E., Meunier, G., Foggia, A., and Reyne, G. Simulation of induction machine operation using a step by step finite element method. IEEE Trans. Magnet., 1991, 27, 5232-5234.

24 Anon. 2. Ace, modified version 3.1, ABB common platform for field analysis and simulations. ABB Corporate Research Centre, $\mathrm{ABB} \mathrm{AB}$, Corporate Research, Västerås, Sweden.

25 Dahlgren, M., Frank, H., Leijon, M., Owman, F., and Walfridsson, L. Windformer - wind power goes large scale. ABB Rev., 2000, 3, 31-37.

26 Leijon, M. and Liu, R. Energy technologies: electric power generators, vol. 3, 2002, pp. 151-164 (Landolt-Börnstein).

27 Leijon, M., Dahlgren, M., Walfridsson, L., Ming, L. and Jaksts, A. Windformer - a recent development in the electrical insulation systems of generators and transformers. IEEE Electric. Insul. Mag., 2001, 17(3), 10-15.

28 Draka product information, available from http://www. draka.se, accessed 25 September 2007.

29 Waters, R., Stalberg, M., Danielsson, O., Svensson, O., Gustafsson, S., Strömstedt, E., Eriksson, M., Sundberg, J., and Leijon, M. Experimental results from sea trials of an offshore wave energy system. Appl. Phys. Lett., 2007, 90, 034105 .

30 Eriksson, S. Vertical axis wind turbines with direct driven generators. UURIE 302-06L, Uppsala, 2006.
31 Jadric, I., Borojevic, D., and Jadric, M. Modeling and control of a synchronous generator with an active DC load. IEEE Trans. Power Electron., 2000, 15(2), 303-311.

32 Esmaili, R., Xu, L., and Nichols, D. K. A new control method of permanent magnet generator for maximum power tracking in wind turbine application. In the IEEE Power Engineering Society General Meeting, vol. 3, 2005, pp. 2090-2095.

33 Danielsson, O., Leijon, M., and Sjöstedt, E. Detailed study of the magnetic circuit in a longitudinal flux permanent-magnet synchronous linear generator. IEEE Trans. Magnet., 2005, 41(9), 2490-2495.

34 Product information, hysteresis data for M800-100A, available from http://www.sura.se, accessed 25 September 2007.

35 N35 provided by Sura Magnets $A B$, available from http://www.suramagnets.se/pdf/suramagnets_sintered_ nd-fe-b.pdf, accessed 25 September 2007.

36 Gupta, R., Yoshino, T., and Saito, Y. Finite element solution of permanent magnetic field. IEEE Trans. Magnet., 1990, 26(2), 383-386.

37 IEEE Guide 115-1995: Test procedures for synchronous machines, part I-Acceptance and performance testing; part II-Test procedures and parameter determination for dynamic analysis. IEEE, 1 May 1995, $192 \mathrm{pp}$.

38 SKF - Product information and models to calculate losses, available from www.skf.com, accessed 25 September 2007.

39 SEW K127DV180L4/BM/TF, available from http://www. sew-euro drive.se/.

40 ACS800-01-0050-3. ABB Motors and Drives, available from http://www. abb.com.

41 HS300 standard resistors from Arcol, available from www.arcolresistors.com, accessed 22 October 2007.

42 KS 300.6 heat sinks from Austerlitz Electronics, available from http://www.austerlitz-electronic.de, accessed 22 October 2007. 